\title{
Mate Value Discrepancy and Attachment Anxiety Predict the Perpetration of Digital Dating Abuse
}

\author{
Manpal Singh Bhogal (Psychology Department, Staffordshire University, ST1 2DE, UK) \& Jessica M. Howman \\ (Psychology Department, Coventry University, CV1 5FB)
}

\begin{abstract}
Research suggests that individual differences in attachment style predict the perpetration of digital dating abuse. In addition to attachment style, no research, to our knowledge, has explored the role of mate value in the perpetration of digital dating abuse. In this paper, we argue that digital dating abuse is a contemporary cost-inflicting mate retention behaviour, where larger mate value discrepancies between partners are associated with higher levels of digital dating abuse ( $\mathrm{n}=167$ ). As expected, high mate value discrepancy and attachment anxiety were associated with high levels of digital dating abuse. We provide novel support for the relationship between mate value discrepancy and digital dating abuse. Our findings provide support for additional, unexplored factors which lead to the perpetration of digital dating abuse.
\end{abstract}

\section{Introduction}

\section{Digital Dating Abuse}

'Digital dating abuse is broadly defined as harassing, threatening, monitoring, impersonating, humiliating, or verbally abusing one's current partner through the use of technology, such as cell phones, social media, or electronic mail' (see Belknap et al. 2012; Melander 2010; Sugarman and Willoughby 2013, as cited in Wolford-Clevenger et al. 2016, p. 156). Although both online and offline abuse can be detrimental to victims and relationships, abuse which occurs online is particularly invasive, as physical proximity is not required, as compared to offline abuse (Bennett et al. 2011; Zweig et al. 2013). Furthermore, people are not always aware that their partners are engaging in digital dating abuse, which adds to the complexity of researching this issue. The issue is problematic as victims of digital dating abuse often feel isolation and experience symptoms of depression (Teten et al. 2009). As a result, it is imperative that researchers not only focus on the impact this behaviour has on victims but also to elucidate why people engage in digital dating abuse, which is lacking in the literature (Stonard et al. 2014).

Digital dating abuse can take place using social media. Social media is often used to connect with a romantic partner (Elphinston and Noller 2011), particularly amongst young adults, who are one of the heaviest users of digital communication (Sánchez et al. 2015). This ease of communication can be observed on social media platforms, where users can publicly display personal information online (Fox and Anderegg 2014). With the advent of smartphones, this communication goes even further in that access to the internet is not restricted by place or time (Vorderer and Kohring 2013). This continuous connectedness can benefit a romantic relationship, by allowing individuals to be involved in each other's daytoday lives, potentially increasing closeness between a couple (Tokunaga 2011). However, there is the potential for the availability of personal information on social media to be abused in romantic relationships, through constantly checking a partner's whereabouts and status updates, leading to intrusion of a partner's privacy (Van Ouytsel et al. 2016). Furthermore, the highly public nature of social media provides greater opportunity to humiliate a partner, because embarrassing media and private information can be rapidly shared with others (Bennett et al. 2011).For some, access to personal information, coupled with continuous online contact, may blur the digital boundaries of what constitutes as inappropriate behaviour towards a romantic partner, thus constituting digital dating abuse (Reed et al. 2016b).

Social media can provide a wealth of information about a partner, which may become a prominent source of jealousy, because individuals can observe their partners' interactions with others, including potential romantic rivals (Fox et al. 2014). Those who are predisposed to experience jealousy in romantic relationships may be at risk of carrying out intrusive or abusive behaviour towards their partner online (Seiffge, Krenke and Burk 2015). In support, recent evidence suggests that those who report high levels of behavioural jealousy and hostility report higher levels of engagement in digital dating abuse (Deans and Bhogal in press). 
Attachment Theory and Digital Dating Abuse

Attachment theory has been successfully applied to understanding romantic relationships (Hazan and Shaver 1987). Romantic relationships are thought to be experienced differently depending on individual attachment histories and styles, in which patterns of behaviour towards one's primary caregiver during infant years are mirrored with romantic partners in later life (Waters et al. 2000). Avoidant adults tend to experience an excessive need for self-reliance and fear of intimacy, whereas anxious individuals tend to experience an excessive need for approval and fear of abandonment (Wei et al. 2007). Attachment style has been identified as a consistent predictor of several relationship features, such as relationship satisfaction (Campbell et al. 2005), irrational beliefs (Stackert and Bursik 2003) and intimate partner violence (Dutton and White 2012). Attachment theory is a useful framework for conceptualising how both healthy and unhealthy forms of love originate as adaptations to early social experiences (Stackert and Bursik 2003).

Individuals with differing attachment styles have varied expectations of their partners. The intense desire to feel close to romantic partners, coupled with a fear of abandonment, may explain why anxious individuals tend to perpetrate more intrusive behaviours against their partners online. Greater attachment anxiety has been associated with more frequent perpetration of digital dating abuse, even after controlling for demographic characteristics, such as hours spent using social networking sites and reports of victimisation (Reed et al. 2016b). To our knowledge, Reed et al. $(2015,2016 \mathrm{~b})$ are the only researchers to explore the relationship between attachment anxiety and digital dating abuse. We attempted to replicate the findings of Reed et al. (2015).

Due to high levels of relationship anxiety, anxious individuals tend to experience the highest levels of relationship uncertainty and may attempt to reduce their anxiety through monitoring their partner online (Fox and Warber 2014). Due to a lack of previous research exploring attachment style and digital dating abuse, it was important to further explore the findings of Reed et al. (2015), who found that that those who reported higher levels of attachment anxiety also reported higher levels of electronic intrusive behaviour. As avoidant individuals do not engage in proximity-seeking behaviour (Barbaro et al. 2016), greater attachment avoidance is associated with less frequent engagement in digital dating abuse (Reed et al. 2015). This may be because avoidant individuals are more likely to engage in casual sex, rather than having committed, long-term relationships (Drouin and Landgraff 2012). As a result of the aforementioned literature exploring the strong links between attachment dimensions and several relational factors, we applied attachment theory to further understand digital dating abuse.

\section{Mate Value and Mate Retention Behaviour}

Mate value refers to the total value of characteristics that an individual possesses in terms of the potential contribution to his or her mate's reproductive success (Waynforth 2001). When choosing romantic partners, people engage in assortative mating in relation to mate value, i.e. they chose partners who are similar to themselves in terms of mate quality. Mate value discrepancies between one and one's partner can predict several relationship outcomes such as forgiveness and relationship satisfaction (Conroy-Beam et al. 2016; Sidelinger and Booth-Butterfield 2007). These findings suggest that mate value can influence the formation of romantic relationships, as well as several factors associated with the maintenance of romantic relationships.

Once a mate has been obtained, the risk of mate poaching (in which a mate is lured away by a rival) is an adaptive problem. For women, the presence of a mate poacher risks the resources acquired through her mate being diverted away from her and her offspring, and towards a rival. For men, there is a risk of cuckoldry (unwillingly raising offspring which is not biologically related to the male). Furthermore, recent evidence suggests that self-perceived mate value positively predicts likelihood of engaging in mate poaching (Erik and Bhogal 2016). These risks associated with mate poaching can be reduced by employing mate retention behaviours. Mate retention is a key to the maintenance of romantic relationships. Mate retention behaviours are often performed to reduce the likelihood of partner infidelity and relationship termination (Buss and Shackelford 1997), which can vary between sexes. For example, in research exploring men's use of mate retention behaviour in marriages, it has been found that a husband's self-esteem predicts likelihood of engaging in mate retention tactics (see Holden et al. 2014). Furthermore, recent evidence suggests that those who have anxious attachment styles often engage in mate retention behaviours (Barbaro et al. in press). The above findings suggest personality traits could influence likelihood of engaging in mate retention strategies.

Mate retention behaviours can be grouped into two categories: benefit-provisioning and cost-inflicting. Benefitprovisioning mate retention behaviours function to retain a mate through use of compliments or gifts, whereas costinflicting mate retention behaviours rely on risky behaviour, with the aim of inflicting costs for not remaining in the relationship (Starratt and Shackelford 2012).Cost-inflicting mate retention is characterised by abuse, posturing, manipulation and the monopolisation of time rendering attempts to defect from the relationship costly and dangerous (Miner et al. 2009). Men of a higher mate value 
frequently perform benefit-provisioning behaviour compared to men of a lower mate value, who often perform more cost-inflicting behaviour (Miner et al. 2009). Mates of higher mate value have greater access to the mating market, and therefore have greater opportunity to commit infidelity or defect from their current relationship (Starratt et al. 2016). Lower value mates may be unable to directly compete with rivals of higher mate value, and therefore resort to cost inflicting mate retention behaviours by reducing their partner's self-esteem and their partner's chances of acquiring a new romantic partner (Miner et al. 2009).

The links between cost-inflicting mate retention behaviour and digital dating abuse are evident through the fact that both behaviours involve manipulation, controlling and invasive behaviour. Recent measures of mate retention rarely include the use of digital mediums in retaining a mate, providing a strong rationale for this study. We argue that digital dating abuse may be a contemporary form of a costinflicting mate retention behaviour, perhaps through sabotaging covert poaching attempts made online by rivals. For example, Brem et al. (2015) explored online and offline mate retention behaviour and partner-directed aggression (towards physical and psychological) using the Facebook Mate Retention Tactics Inventory. They found that online partner surveillance using Facebook was positively related to partner-directed psychological aggression. Furthermore, they found that men and women often engage in mate retention strategies online through the use of Facebook. Their finding provides a further rationale for delving into the use of mate retention strategies online, and the factors which are associated with the perpetration of this behaviour.

\section{Mate Value Discrepancy}

When we chose a mate, we are guided by evolutionary mechanisms. We aim to find mates who possess most, if not all, the preferences we seek in a partner. However, this is not always the case, as we can be in a relationship with a partner who does not possess all the qualities we seek (lower mate value compared to ourselves). However, according to Conroy-Beam et al. (2016), the discrepancy between what we want and what we get is not entirely clear, thus increasing the need to explore the role of mate value discrepancy in the functionality of romantic relationships.

When exploring mate retention behaviours, it is important to take mate value discrepancy into account, as opposed to mate value alone. This is because if one has a partner high in mate value, and consider themselves to have high mate value, mate retention behaviours are less likely to occur, due to reduced threat of relationship termination. On the other hand, in relationships where an individual has a partner high in mate value compared to themselves, mate retention behaviours are more likely to occur, as individuals can experience more costs if their partner defects from the relationship and seeks a mate of higher mate value. As a result, people engage in cost-inflicting mate retention behaviours if they perceive there is a potential risk to the relationship, particularly if they have a partner of a higher mate value compared to themselves.

Digital dating abuse may be a contemporary form of mate retention behaviours. As a result, it is important to explore the role of mate value discrepancy in the perpetration of digital dating abuse; as according to Conroy-Beam etal. (2016), there is little research exploring the factors which influence relationship outcomes once a romantic relationship has been established. Mate value discrepancy has been found to be a significant predictor of forgiveness and jealousy (see Sidelinger and Booth-Butterfield 2007) and relationship satisfaction (Conroy-Beam et al. 2016). Conroy-Beam et al. (2016) suggest that mate value discrepancy can help researchers to explore the frequency and intensity of mate retention behaviours. Furthermore, they argue that if the discrepancy between one and one's partner is high (partner has higher mate value than us), they are difficult to replace.

\section{Digital Dating Abuse as a Mate Retention Behaviour}

Although we have discussed attachment style and digital dating abuse, attachment style is also associated with the use of mate retention behaviours as anxious individuals perform more mate retention behaviours than avoidant individuals (Barbaro et al. 2016). This may be because anxious individuals are hyper-vigilant to rejection cues from their partner, are fearful of abandonment (Barbaro et al. 2016) and are likely to perceive relationship uncertainty (Hudson and Fraley 2017). Mate retention is performed less frequently by avoidant men, which might result from a general evasion of proximity seeking behaviours (Barbaro et al. 2016). In addition, an established and commonly used measure of mate retention known as the Mate Retention Inventory-Short Form (MRISF; Buss et al. 2008) shares similarities with the digital dating abuse measure used in this study. Vigilance, concealment and derogation of mate on the MRI-SF have digital dating abuse equivalents, such as monitoring a partner's other relationships or whereabouts, interfering in a partner's other relationships, spreading rumours or distributing embarrassing photos or videos of a partner (Reed et al. 2016a). Except for a few items, behaviours on the MRI-SF tend to rely on public displays of affection, commitment, possession or being able to directly observe the threat of rivals in social settings (Buss et al. 2008), suggesting there are parallels between digital dating abuse and mate retention behaviour. However, relationships are increasingly adopting an online format (Lucero et al. 2014), and these public displays and 
observations can also be performed using social media through relationship status updates and photos (Fox and Anderegg 2014), increasing the likelihood that digital dating abuse may be a cost-inflicting mate retention behaviour.

\section{Aims and Hypotheses}

Taking the aforementioned research into account, we argue that digital dating abuse can act as a contemporary form of mate retention behaviours, with the purpose of constantly reassuring us that our partners are not engaging in infidelity and 'straying' from the relationship. This is evident by the finding that people of high mate value engage in mate poaching more often than those with low mate value (Erik and Bhogal 2016), and those of high mate value are likely to be poached by alternative mates. Digital communication is prominent in our day-to-day lives. Therefore, it is imperative that researchers explore contemporary mate retention behaviours occurring in the online world. Although both online and offline dating abuse aim to control, threaten and harass a romantic partner, digital dating abuse can occur without the partner's awareness, as digital dating abuse does not require physical proximity compared to offline dating abuse. Although research suggests that mate value discrepancy predicts intimate partner violence (see Buss and Duntley 2011; Arnocky et al. 2015; Kaighobadi et al. 2009 for research on partnerdirected violence and mate retention strategies), no research (to our knowledge) has explored whether mate value discrepancy predicts digital dating abuse.

This study had three aims. First, we aimed to corroborate previous evidence for the relationship between attachment style and digital dating abuse (e.g. Reed et al. 2015). As a result, attachment avoidance was predicted to be negatively associated with digital dating abuse (H1), and attachment anxiety to be positively associated with digital dating abuse (H2).

Secondly, we aimed to examine whether mate value discrepancy predicted digital dating abuse as a contemporary form of cost-inflicting mate retention behaviours. We expected mate value discrepancy to be positively related to the perpetration of digital dating abuse (H3). Demographic characteristics were obtained, such as the participants' gender, as men have been found to engage in digital dating abuse more frequently than women (Deans and Bhogal in press).

\section{Method}

\section{Design and Participants}

A cross-sectional correlational design was adopted to explore whether attachment styles (anxious and avoidant), gender and mate value discrepancy predicted the perpetration of digital dating abuse. Initially, 180 participants took part, with data from 13 participants being removed due to extreme outliers and/or missing data (outliers were identified and removed using Casewise diagnostics in SPSS). The final sample comprised of 167 participants, recruited at a UK university, via the department's research participation scheme (46 men, 121 women, mean age $=22.20$ years old, $\mathrm{SD}=4.88$; mean relationship length $=27.59$ months, $\mathrm{SD}=33.16$ ). Eighty-six participants took part via the department's online survey system (SONA), and 81 participants took part via the Bristol Online Survey (www.onlinesurveys.ac.uk).

Participants were required to currently be in a committed, heterosexual relationship because many mate retention behaviours are performed in long-term relationships (Buss 1988). We recruited heterosexual participants due to the evolutionary explanations being tested. To guide our anticipated sample size, an a-priori power analysis was conducted using G*Power (Faul et al. 2009). To achieve $80 \%$ power (medium effect size of .25 with 4 predictors and an alpha level of .05 , all for multiple regression), $G *$ Power recommended 53 participants, which we surpassed. Materials

\section{Attachment Style}

The 12-item Experiences in Close Relationships Scale-Short Form (ECR-S; Wei et al. 2007) provides a measure of individual attachment style on two dimensions: attachment avoidance and attachment anxiety. Each has its own subscale with six items each, scored on a 7-point Likert scale ranging from ' $1=$ Strongly disagree to $7=$ Strongly agree. The avoidant sub-scale includes items such as 'I try to avoid getting too close to my partner, and the anxiety sub-scale includes items such as 'My desire to be very close sometimes scares people away'. Both sub-scales were found to be reliable in our sample (avoidance $\alpha=.86$, anxiety $\alpha=$ .78).

\section{Mate Value}

The 17-item Mate Value Inventory Short Form (MVI-7; Kirsner et al. 2003) was presented to participants twice (counterbalanced). Participants were instructed to score themselves (self-mate value) and to score their current romantic partner using the same 17 items (partner-mate value). The MVI-7 lists 17 characteristics which are scored on a 7-point Likert scale ranging from ' $-3=$ Extremely low on this characteristic to $+3=$ Extremely high on this characteristic' and a mean score is calculated for each subscale. For simplicity, we altered the points to range from ' 1 $=$ Extremely low on this characteristic to $7=$ Extremely high on this characteristic'. Example items include 'attractive 
face' and 'financially secure'. Cronbach's alpha for selfmate value $(\alpha=.73)$ and partner-mate value $(\alpha=.80)$ were reliable.

Participants self-reported their mate value as well as their partner's mate value (as both self and partner-mate values predict the use of mate retention behaviours, see Miner et al. 2009). Consistent with Sela et al. (2016), we calculated mate value discrepancy by computing the difference between the participants' self and partner mate values.

\section{Digital Dating Abuse}

The 19-item perpetration sub-scale of the Digital Dating Abuse scale measures participants' perpetration of digital dating abuse (Reed et al. 2016a). Participants were instructed to score each item by how frequently they have carried out each behaviour in their relationship, on a 4-point Likert scale ranging from ' $0=$ Never to $3=$ Very often'. An example item is 'Looked at my partner's private information on a computer or mobile phone without permission'. The scale was reliable in our sample $(\alpha=.80)$.

\section{Procedure}

Once participants provided informed consent, they were asked to provide demographic details and complete the questionnaires outlined above. Finally, participants were fully debriefed. Data were collected anonymously, online, using SONA (departmental survey builder).

\section{Results}

Analyses were conducted using a combination of JASP (JASP team 2018) and SPSS. Descriptive statistics are presented in Table 1. Bivariate Pearson's correlations between all variables are presented in Table 2 .

There was no correlation between attachment avoidance and digital dating abuse. A small to moderate (positive) correlation was found between attachment anxiety and digital dating abuse perpetration, and a small (positive) correlation was found between mate value discrepancy and digital dating abuse.

\section{Multiple Regression}

Multiple regression was conducted to predict digital dating abuse (see Table 3 for statistics derived from the analysis)

Table 1 Descriptive statistics relating to all key variables

\begin{tabular}{lccc}
\hline Variable & Mean (SD) & Min & Max \\
\hline Attachment avoidance & $1.44(.35)$ & 1.00 & 2.42
\end{tabular}

\begin{tabular}{lrrr} 
Attachment anxiety & $1.89(.33)$ & 1.15 & 2.65 \\
Self mate value & $2.26(.12)$ & 1.96 & 2.56 \\
Partner mate value & $2.34(.13)$ & 1.97 & 2.62 \\
Mate value discrepancy & $-.08(.13)$ & -.42 & .38 \\
Digital dating abuse & $1.43(.85)$ & .00 & 3.46 \\
\hline
\end{tabular}

from attachment avoidance, attachment anxiety, mate value discrepancy and the participants' gender. Preliminary analyses were conducted to ensure no violation of the assumptions of normality, linearity, multicollinearity, homoscedasticity and independent errors. The model explained $10.7 \%$ of the variance in digital dating abuse, $F$ $(4,162)=4.83, \mathrm{R}^{2}=.107\left(\right.$ adjusted $\left.\mathrm{R}^{2}=.085\right), p<.001$. Attachment anxiety and mate value discrepancy were significant positive predictors of digital dating abuse as opposed to attachment avoidance and the participants' gender, which were non-significant predictors of digital dating abuse.

\section{Discussion}

The aim of this research was to explore the relationships amongst attachment anxiety, mate value discrepancy and digital dating abuse. Our findings suggest that those who reported higher attachment anxiety engaged in higher levels of digital dating abuse perpetration, thus supporting H1. Our findings indicated a very small relationship between attachment avoidance and digital dating abuse, thus not supporting $\mathrm{H} 2$.

A further key aim of our study was to explore whether mate value discrepancy was related to digital dating abuse, with our argument grounded in the rationale that digital dating abuse is a contemporary form of a cost-inflicting mate retention behaviour. We suggested those who have greater mate value discrepancy between themselves and their partner perpetrate higher levels of digital dating abuse towards their partner. Hypothesis 3 was supported as those reporting higher mate value discrepancy reported engaging in higher digital dating abuse towards their partners, which to our knowledge has not

Table 2 Bivariate correlations between attachment anxiety, attachment avoidance, mate value discrepancy and digital dating abuse

\begin{tabular}{lcccc}
\hline & 1 & 2 & 3 & 4 \\
1. Avoidant attachment & - & .13 & $.27 * *$ & .04 \\
2. Anxious attachment & - & - & .02 & $.27 * *$ \\
3. Mate value discrepancy & - & - & - & $.16^{*}$ \\
4. Digital dating abuse & - & - & - & - \\
& & & & \\
\hline$* \mathrm{p}<.01, * \mathrm{p}<.05$ & & & &
\end{tabular}


Table 3 Results of the multiple regression model predicting digital dating abuse from gender, attachment avoidance, attachment anxiety and mate value discrepancy

\begin{tabular}{|c|c|c|c|c|c|c|c|}
\hline Variable & $\beta$ & $\mathrm{p}$ & $\mathrm{t}$ & CI $(95 \%)$ & & Tolerance & VIF \\
\hline Gender & 0.09 & .245 & 1.17 & -0.12 & 0.45 & .995 & 1.047 \\
\hline Avoidance & -0.3 & .724 & -0.35 & -0.44 & 0.30 & .905 & 1.105 \\
\hline Anxiety & 0.27 & $<.001 * *$ & 3.61 & 0.32 & 1.09 & .981 & 1.020 \\
\hline Mate value discrepancy & 0.18 & $.025^{*}$ & 2.26 & 0.14 & 2.12 & .905 & 1.105 \\
\hline
\end{tabular}

been previously explored in the literature. This finding opens a new and exciting avenue when exploring evolutionary mechanisms behind online dating behaviour. Furthermore, we provide further understanding of the determinants of such an important issue, which can have devastating effects on victims of digital dating abuse.

Attachment avoidance was a non-significant predictor of digital dating abuse, in that avoidant individuals did not perpetrate less frequent digital dating abuse. This is inconsistent with previous research in that avoidance has been found to be associated with less frequent perpetration of digital dating abuse (Reed et al. 2015). This finding also diverges from attachment theory, as avoidant individuals are typically characterised as self-reliant and evasive of intimacy (Wei et al. 2007). However, we may have inadvertently limited the potential strength of scores on the avoidance dimension by only including participants with experiences of being in committed romantic relationships, thus failing to sample truly avoidant individuals. This prerequisite may have limited avoidance scores because avoidant individuals tend to engage in casual sex as opposed to committed relationships (Drouin and Landgraff 2012). Avoidance was not associated with digital dating abuse even though avoidant individuals tend to appraise their partners more negatively than anxious individuals, who are usually critical of their partners (Hudson and Fraley 2017).

Attachment anxiety was a significant predictor of digital dating abuse, in that anxious individuals did perpetrate more frequent digital dating abuse, consistent with previous research (Reedetal. 2015).This finding was also consistent with attachment theory, in that anxious individuals are characterised as being dependent and fearful of abandonment (Wei et al. 2007), suggesting that digital dating abuse may be used by individuals with anxious attachment styles as a means of retaining their romantic partner. This is the first demonstration of this relationship in a UK sample, and replicates the findings of Reed et al. (2015) who conducted their study with a US sample.

Our study has also provided the first demonstration of an association between higher mate value discrepancy and increased digital dating abuse perpetration. Our data indicate that digital dating abuse may be a contemporary cost inflicting mate retention behaviour, perpetrated by those who have a larger mate value discrepancy between themselves and their partner. This novel finding has the potential to pave future research exploring mate value and digital dating abuse, particularly as romantic relationships are adopting an online format, at both initiation, and throughout the relationship. Our findings add to the limited literature exploring the factors that predict why people engage in digital dating abuse. The more factors we are aware of, the more influential psychological research can be in engaging with policy, reducing partner violence and protecting privacy online, such as increasing awareness amongst partners of what constitutes digital dating abuse.

\section{Limitations and Future Research}

Although some may argue that self-report methods may not be the most effective method of gathering data, due to the sensitive nature of the topic, the fact that participants remained anonymous and the questionnaire took place online may been effective in drawing out honest responses (Drouin and Landgraff 2012). Furthermore, future research should control for previous experience of infidelity, as recent research has explored the role of perceived risk of infidelity in attachment style and mate retention behaviour (Barbaro et al. in press). Future research could explore whether those who have been victims of sexual infidelity engage in higher levels of digital dating abuse to identify cues of potential infidelity.

We operationalised mate value discrepancy by calculating the difference between self and partner mate value. Although we provided a quantifiable measure of mate value discrepancy, recent research has adopted an alternative method for calculating mate value discrepancy. For example, Conroy-Beam et al. (2016) adopted a multivariate method, by calculating Euclidean distances between mate preferences and partner qualities. Furthermore (see study 3 of their paper), they calculated Euclidean measures of mate value and mate value discrepancies relating to self and partner mate value. As a result, future research could explore the role of mate value 
discrepancy in the perpetration of digital dating abuse using Euclidean distances. However, we were primarily interested in self mate value and the participants' perception of their partners mate value, as opposed to asking participants to rate their ideal partner. Finally, researchers suggest that difference in scores have reduced reliability (Peter et al. 1993). Researchers could use response surface analysis for further data of this nature (see Shanock et al. 2010, 2014).

\section{Conclusion}

Our findings provide new evidence of the important roles of attachment style and mate value discrepancy in the perpetration of digital dating abuse. We provide support for the relationship between mate value discrepancy, attachment style and digital dating abuse perpetration in the UK. Our findings provide evidence that mate value discrepancy predicts digital dating abuse perpetration as a contemporary form of a costinflicting mate retention behaviour, adopting an evolutionary framework.

Acknowledgments We thank James E Bartlett, Robert Dempsey, Alison Owen and Maria Panagiotidi for their valuable comments on an earlier draft of this manuscript.

\section{Compliance with Ethical Standards}

Conflict of Interest The authors declare that they have no conflict of interest.

\section{References}

Arnocky, S., Sunderani, S., Gomes, W., \& Vaillancourt, T. (2015). Anticipated partner infidelity and men's intimate partner violence: the mediating role of anxiety. Evolutionary Behavioral Sciences, 9(3), 186-196.

Barbaro, N., Pham, M. N., Shackelford, T. K., \& Zeigler-Hill, V. (2016). Insecure romantic attachment dimensions and frequency of mate retention behaviors. Personal Relationships, 23, 605-618.

Barbaro, N., Sela, Y., Atari, M., Shackleford, T. K., \& Zeigler-Hill, V. (in press). Romantic attachment and mate retention behaviour. Journal of Social and Personal Relationships., 026540751774933. https:// doi.org/10.1177/0265407517749330.

Belknap, J., Chu, A. T., \& Deprince, A. P. (2012). The roles of phones and computers in threatening and abusing women victims of male intimate partner abuse. Duke Journal of Gender Law and Policy, 19(2), 373-406.

Bennett, D. C., Guran, E. L., Ramos, M. C., \& Margolin, G. (2011). College students' electronic victimization in friendships and dating relationships: anticipated distress and associations with risky behaviors. Violence and Victims, 26(4), 410-429.

Brem, M. J., Spiller, L. C., \& Vandehey, M. A. (2015). Online materetention tactics on Facebook are associated with relationship aggression. Journal of Interpersonal Violence, 30, 2831-2850.
Buss, D. M. (1988). From vigilance to violence: tactics of mate retention in american undergraduates. Ethology and Sociobiology, 9(5), 291-317.

Buss, D. M., \& Duntley, J. D. (2011). The evolution of intimate partner violence. Aggression and Violent Behavior, 16(5), 411-419.

Buss, D. M., \& Shackelford, T. K. (1997). From vigilance to violence: mate retention tactics in married couples. Journal of Personality and Social Psychology, 72, 346-361.

Buss, D. M., Shackelford, T. K., \& McKibbin, W. F. (2008). The Mate Retention Inventory-Short Form (MRI-SF). Personality and Individual Differences, 44, 322-334.

Campbell, L., Simpson, J. A., Boldry, J., \& Kashy, D. A. (2005). Perceptions of conflict and support in romantic relationships: the role of attachment anxiety. Journal of Personality and Social Psychology, 88(3), 510-531.

Conroy-Beam, D., Goetz, C. D., \& Buss, D. M. (2016). What predicts romantic relationship satisfaction and mate retention intensity: mate preference fulfilment or mate value discrepancies? Evolution and Human Behavior, 37, 440-448.

Deans, H., \& Bhogal, M. S. (in press). Perpetrating cyber dating abuse: the role of aggression, romantic jealousy and gender. Current Psychology. https://doi.org/10.1007/s12144-017-9715-4.

Drouin, M., \& Landgraff, C. (2012). Texting, sexting, and attachment in college students' romantic relationships. Computers in Human Behavior, 28, 444-449.

Dutton, D. G., \& White, K. R. (2012). Attachment insecurity and intimate partner violence. Aggression and Violent Behavior, 17, 475-481.

Elphinston, R. A., \& Noller, P. (2011). Time to face it! Facebook intrusion and the implications for romantic jealousy and relationship satisfaction. Cyberpsychology, Behavior, and Social Networking, 14(11), 631-635.

Erik, E., \& Bhogal, M. S. (2016). Do the dark triad and self-perceived mate value predict intention to mate poach? Letters on Evolutionary Behavioral Science, 7(2), 1-4.

Faul, F., Erdfelder, E., Buchner, A., \& Lang, A. G. (2009). Statistical power analyses using $G^{*}$ Power 3.1: tests for correlation and regression analyses. Behavior Research Methods, 41, 1149-1160.

Fox, J., \& Anderegg, C. (2014). Romantic relationship stages and social networking sites: uncertainty reduction strategies and perceived relational norms on Facebook. Cyberpsychology, Behavior, and Social Networking, 17(11), 685-691.

Fox, J., \& Warber, K. M. (2014). Social networking sites in romantic relationships: attachment, uncertainty, and partner surveillance on Facebook. Cyberpsychology, Behavior, and Social Networking, 17(1), 3-7.

Fox, J., Osborn, J. L., \& Warber, K. M. (2014). Relational dialectics and social networking sites: the role of Facebook in romantic relationship escalation, maintenance, conflict and dissolution. Computers in Human Behavior, 35, 527-534.

Hazan, C., \& Shaver, P. (1987). Romantic love conceptualized as an attachment process. Journal of Personality and Social Psychology, 52(3), 511-524.

Holden, C. J., Shackleford, T. K., Zeigler-Hill, V., Miner, E. J., Kaighobadi, F., Starratt, V. G., Jeffrey, A. J., \& Buss, D. M. (2014). Husband's esteem predicts his mate retention tactics. Evolutionary Psychology, 12(3), 655-672.

Hudson, N. W., \& Fraley, R. C. (2017). Adult attachment and perceptions of closeness. Personal Relationships, 24(1), 17-26.

JASP Team. (2018). JASP (Version 0.8.0.0) [Computer software].

Kaighobadi, F., Shackleford, T. K., Popp, D., Moyer, R. M., Bates, V. M., \& Liddle, J. R. (2009). Perceived risk of female infidelity moderates the relationship between men's personality and partner-directed violence. Journal of Research in Personality, 43 , 1033-1039. 
Kirsner, B. R., Figueredo, A. J., \& Jacobs, W. J. (2003). Self, friends, and lovers: structural relations among Beck Depression Inventory scores and perceived mate values. Journal of Affective Disorders, $75,131-148$.

Lucero, J. L., Weisz, A. N., Smith-Darden, J., \& Lucero, S. M. (2014). Exploring gender differences: socially interactive technology use/ abuse among dating teens. Affilia: Journal of Women and Social Work, 29(4), 478-491.

Melander, L. (2010). College students' perceptions of intimate partner cyber harassment. Cyberpsychology, Behavior, and Social Networking, 13(3), 263-268.

Miner, E. J., Starratt, V. G., \& Shackelford, T. K. (2009). It's not all about her: Men's mate value and mate retention. Personality and Individual Differences, 47, 214-218.

Peter, J. P., Churchill, G. A., \& Brown, T. J. (1993). Caution in the use of difference scores in consumer research. Journal of Consumer Research, 19, 655-662.

Reed, L. A., Tolman, R. M., \& Safyer, P. (2015). Too close for comfort: attachment insecurity and electronic intrusion in college students' dating relationships. Computers in Human Behavior, $50,431-438$.

Reed, L. A., Tolman, R. M., \& Ward, L. M. (2016a). Snooping and sexting: digital media as a context for dating aggression and abuse among college students. Violence Against Women, 22(13), 1-21.

Reed, L. A., Tolman, R. M., Ward, L. M., \& Safyer, P. (2016b).

Keeping tabs: attachment anxiety and electronic intrusion in high school dating relationships. Computers in Human Behavior, 58, 259-268.

Sánchez, V., Muñoz-Fernández, N., \& Ortega-Ruíz, R. (2015). Cyberdating Q_A: an instrument to assess the quality of adolescent dating relationships in social networks. Computers in Human Behavior, 48, 78-86.

Seiffge-Krenke, I., \& Burk, W. J. (2015). The dark side of romantic relationships: aggression in adolescent couples and links to attachment. Mental Health and Prevention, 3, 135-142.

Sela, Y., Mogilski, J. K., Shackelford, T. K., Zeigler-Hill, V., \& Fink, B. (2016). Mate value discrepancy and mate retention behaviors of self and partner. Journal of Personality, 84(5), 560-571.

Shanock, L. R., Baran, B. E., Gentry, W. A., Pattison, S. C., \& Heggestad, E. D. (2010). Polynomial regression with response surface analysis: a powerful approach for examining moderation and overcoming limitations of difference scores. Journal of Business and Psychology, 25, 543-554.

Shanock, L. R., Baran, B. E., Gentry, W. A., Pattison, S. C., \& Heggestad, E. D. (2014). Erratum to: polynomial regression with response surface analysis: a powerful approach for examining moderation and overcoming limitations of difference scores. Journal of Business and Psychology, 29, 161.

Sidelinger, R. J., \& Booth-Butterfield, M. (2007). Mate value discrepancy as predictor of forgiveness and jealousy in romantic relationships. Communication Quarterly, 55(2), 207-223.

Stackert, R. A., \& Bursik, K. (2003). Why am I unsatisfied? Adult attachment style, gendered irrational relationship beliefs, and young adult romantic relationship satisfaction. Personality and Individual Differences, 34, 1419-1429.

Starratt, V. G., \& Shackelford, T. K. (2012). He said, she said: men's reports of mate value and mate retention behaviors in intimate relationships. Personality and Individual Differences, 53, 459462.

Starratt, V. G., Weekes-Shackelford, V., \& Shackelford, T. K. (2016). Mate value both positively and negatively predicts intentions to commit an infidelity. Personality and Individual Differences, 104, $18-22$.

Stonard, K., Bowen, E., Lawrence, T., \& Price, S. (2014). The relevance of technology to the nature, prevalence and impact of adolescent dating violence and abuse: a research synthesis. Aggression and Violent Behavior, 19(4), 390-417.

Sugarman, D. B., \& Willoughby, T. (2013). Conceptual issues raised by the rapidly changing social environment. Psychology of Violence, 3(1), 1-8.

Teten, A., Ball, B., Valle, L., Noonan, R., \& Rosenbluth, B. (2009). Considerations for the definition, measurement, consequences, and prevention of dating violence victimization among adolescent girls. Journal of Women's Health, 18(7), 923-927.

Tokunaga, R. S. (2011). Social networking site or social surveillance site? Understanding the use of interpersonal electronic surveillance in romantic relationships. Computers in Human Behavior, 27, 705- 713.

Van Ouytsel, J., Van Gool, E., Walrave, M., Ponnet, K., \& Peeters, E. (2016). Exploring the role of social networking sites within adolescent romantic relationships and dating experiences. Computers in Human Behavior, 55, 76-86.

Vorderer, P., \& Kohring, M. (2013). Permanently online: a challenge for media and communication research. International Journal of Communication, 7, 188-196.

Waters, E., Merrick, S., Treboux, D., Crowell, J., \& Albershein, L. (2000). Attachment security in infancy and early adulthood: a twenty-year longitudinal study. Child Development, 71(3), 684 689.

Waynforth, D. (2001). Mate choice trade-offs and women's preference for physically attractive men. Human Nature, 12(3), 207-219.

Wei, M., Russell, D. W., Mallinckrodt, B., \& Vogel, D. L. (2007). Experiences in Close Relationships Scale (ECR)-short FORM: reliability, validity, and factor structure. Journal of Personality Assessment, 88(2), 187-204.

Wolford-Clevenger, C., Zapor, H., Brasfield, H., Febres, J., Elmquist, J., Brem, M., Shorey, R., \& Stuart, G. (2016). An examination of the partner cyber abuse questionnaire in a college student sample. Psychology of Violence, 6(1), 156-162.

Zweig, J., Lachman, P., Yahner, J., \& Dank, M. (2013). Correlates of cyber dating abuse among teens. Journal of Youth and Adolescence, 43(8), 1306-1321. 